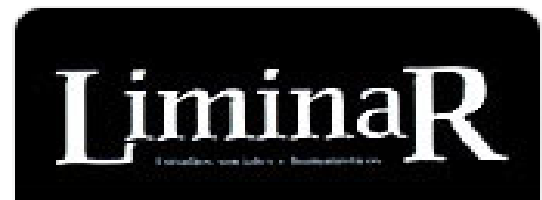

LiminaR. Estudios Sociales y Humanísticos

ISSN: $1665-8027$

liminar.cesmeca@unicach.mx

Centro de Estudios Superiores de México y

Centro América

México

Zúñiga Zenteno, Magda Estrella; Morales Bermúdez, Jesús T.

Fronteras institucionales de pareja, desde la Literatura y el cine en el Sur de México LiminaR. Estudios Sociales y Humanísticos, vol. IX, núm. 2, diciembre, 2011, pp. 43-62

Centro de Estudios Superiores de México y Centro América

San Cristóbal de las Casas, México

Disponible en: http://www.redalyc.org/articulo.oa?id=74522594004

Cómo citar el artículo

- Número completo

- Más información del artículo

- Página de la revista en redalyc.org

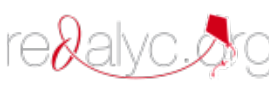

Sistema de Información Científica

Red de Revistas Científicas de América Latina, el Caribe, España y Portugal

Proyecto académico sin fines de lucro, desarrollado bajo la iniciativa de acceso abierto 


\title{
FronterAs INSTITUCIONALES DE PAREJA, DESDE LA LITERATURA y EL CINE EN EL SUR DE MÉXICO
}

\author{
Magda Estrella Zúñiga Zenteno \\ Jesús T. Morales Bermúdez
}

Resumen: El presente trabajo tiene como eje de reflexión la triangulación amorosa en la pareja humana. Como punto de inflexión en el porqué de la triangulación, no desde la antropología, sino desde el psicoanálisis, el trabajo pondera las funciones que cumple, tales como: salvaguardar los límites yoicos, así como fortalecer la relación en la pareja enriqueciendo su vida cotidiana. Una expresión cultural de esta triangulación en México es la figura de "la casa chica", modalidad que funciona como sustento de la familia nuclear o como apéndice de ella. En esta ocasión, como muestra de reproducción de "la casa chica", en todos los sectores y ámbitos de la sociedad, en tanto estructura más o menos legitimada y aceptada socialmente, se lleva a cabo un acercamiento a su puesta en escena en películas del cine nacional y en tres novelas de autores chiapanecos, sin demérito de otras novelas mexicanas, ponderando, desde ellas, las funciones de la amante, a la vezparticulares y diferentes, en el núcleo familiar.

Palabras clave: fronteras, individualidad, pareja, triangulación, familia.

Enviado a dictamen: 25 de abril de 2011

Aprobación: 26 de mayo de 2011

Revisiones: 1

Dra. Magda Estrella Zúñiga Zenteno. Doctora en Psicología Social y Antropología, por la Universidad de Salamanca, España. Investigador Titular de Tiempo Completo del Centro de Estudios Superiores de México y Centroamérica, de la UNICACH. Temas de especialización: Sexualidad y familia, Representaciones en literatura y cine. Correo electrónico: magdazuniga@hotmail.com.

Dr. Jesús T. Morales Bermúdez. Doctor en Antropología, por la Escuela Nacional de Antropología e Historia, México. Investigador Titular de Tiempo Completo del Centro de Estudios Superiores de México y Centroamérica, de la UNICACH. Temas de especialización: Discursos literarios y artísticos; Representaciones simbólicas: políticas, religiosas, de la sexualidad, la familia, el arte. Correo electrónico: mobj47@hotmail.com.
Abstract: The present work has like central idea reflection the loving triangulation in the human pair. As point of inflection in the why of the triangulation, not from anthropology, now from psychoanalysis, the work weighs the functions that fulfill, such as: to safeguard the yoicos limits, to fortify the relation in the pair enriching the daily life of this. An expression culture of this triangulation in Mexico is "the small house", modality that works as sustenance of the nuclear family or like appendix of her. In this occasion, as sample of reproduction of "the small house", in all the sectors and circles of the society, as structure more or less legitimized by the social recognition and its acceptance, is carried out an approach to its putting in scene in films of the national cinema and three novels of chiapanecos authors, without demerit of other Mexican novels, weighing, from them, the functions of the lover, simultaneously particular and different, in the familiar nucleus.

Keywords: borders, individuality, pair, triangulation, family.

$\mathrm{E}$ l trabajo que se presenta a continuación tiene como objeto adentrarnos en el conocimiento de cómo los hombres y las mujeres de ciudades se organizan para formar parejas y luego familias, pero no se detiene en el estudio de la familia o la pareja, sino en una especie de apéndice cultural que requiere para su equilibrio o permanencia: la triangulación. ${ }^{1}$

La triangulación es un fenómeno frecuente en la vida de la pareja humana. El tercero puede encubrir el conflicto en la díada porque este conflicto es desplazado 
a él, tiene la función de propiciar el equilibrio y restablecer los límites subjetivos que se han traspasado en ésta. El tercero puede ser un hijo con problemas de aprendizaje, problemas de salud, con adicciones. Puede ser un familiar-frecuentemente encontramos a "la suegra" como punto de conflicto. El tercero puede estar ubicado en el área laboral o, al establecer relaciones extramaritales, en la figura del o la amante. Es importante aclarar que el tercero también puede estar presente en objetos o actividades cargadas de sentido para uno de los integrantes de la pareja: un deporte, una tesis, un trabajo, una actividad social, cultural, religiosa, etcétera.

Algunos trabajos abocados a los estudios de la familia, pueden dar cuenta de lo que ocurre a nivel micro-familiar en las parejas en general: su actuación social, la reproducción cultural de que son objeto, etcétera. Nuestro trabajo, en cambio, tiene como eje de reflexión teórica uno de los tipos de triangulación de los que hemos mencionado anteriormente, a saber, el fenómeno de la triangulación amorosa como vía para salvaguardar la relación de pareja. Y hablamos de la triangulación amorosa no como un fenómeno excepcional o aislado, sino como un hecho dado, culturalmente aceptado y, en tanto eso, normalizado, según se corrobora en los datos de campo arrojados y sistematizados en un trabajo anterior. ${ }^{2}$ En este sentido, y en forma concreta, nos interesa reflexionar en torno a la función de la figura del amante en la vida de la pareja. Para lograr este objetivo dividimos este trabajo en dos fases:

1. La primera fase propone la triangulación amorosa, la aparición de la amante en la vida de la pareja como una vía emergente para salvaguardar los límites yoicos. El estado de fusión establecido con el enamoramiento muestra que los limites entre el yo y el no yo son lábiles e imperceptibles. En virtud de esto, podemos comprender por qué el amor puede estar tan cercano a la locura, cómo se juega la tensión entre la afirmación del yo o su desaparición en las relaciones de pareja.

2. La segunda fase muestra la triangulación amorosa y su puesta en escena en algunas cintas del cine mexicano, así como su presencia en tres obras de autores chiapanecos: Florinda, de Flavio A. Paniagua; Oficio de tinieblas, de Rosario Castellanos, y La simiente del corsario, de Cesar Coutiño Bezares. Tomamos el cine y la literatura como dos medios para ejemplificar un fenómeno frecuente en la pareja humana, dos medios que se nutren de la realidad social y cultural de la que surgen.

\section{Fronteras yoicas traspasadas al instituirse la pareja}

Lo que significa elegir, constituir y estructurar una pareja, presenta algunos fenómenos complejos. Señala Alejo Spivacow ${ }^{3}$ que la pareja no es sólo la suma de dos sujetos, sino que lo que importa fundamentalmente es lo que recíprocamente activan o desactivan uno en el otro y cómo juntos producen el "entre los dos" (Alejo Spivacow, 2011; 46).

El primero de estos fenómenos muestra que la elección de la pareja es un momento en que se ponen en juego las subjetividades de las dos personas involucradas y, aunque parezcan claros los motivos por los que cada una de ellas se sienta atraída por la otra, en realidad esa atracción aparece todavía como un misterio. La atracción ubica nuestra mirada en una persona, la realza por encima de las demás ante nuestros ojos, la convierte en alguien especial. La elección de la pareja (derivada de esa atracción) no se da por casualidad, ni por azar. Por el contrario, un proceso de repetición de elección de pareja nos evidencia las características de esa pareja elegida, la que pone de manifiesto este dato. Es decir, una segunda o tercera pareja, puede tener rasgos muy parecidos a la primera. Desde allí puede dejarse en claro que en la elección de pareja intervienen factores del orden de 
lo inconsciente, no tan considerados en los estudios sociales, pero no por ello inexistentes. ${ }^{4}$

Si el primer momento de la elección es el atrapamiento de la mirada, la atracción sentida y el impulso por acercarse a un otro, el segundo momento, si hay reciprocidad en el quedar atrapado, es el de forjarse un vínculo amoroso cuya primera característica es la pérdida de los límites yoicos merced a una especie de paraíso en que la diferenciación entre el yo y el no yo es casi imperceptible. Carles Pérez Testor, por ejemplo, dice que puede llamarse enamoramiento a la fuerza o impulso que nos lleva hacia el otro, y que cuando esa fuerza es correspondida, se presentan niveles de fusión simbiótica muy elevados en los miembros de la pareja, lo que conduce a una fusión diádica, a la construcción de un uno mismo en común. ${ }^{5}$ Alberoni señala al tratar de responder qué es el amor, que dos personas, en un momento dado de su vida, comienzan una mutación, se vuelven disponibles para distanciarse de sus anteriores objetos amatorios, de sus vínculos precedentes, para dar origen a una nueva comunidad. Entonces entran en el estado naciente, un estado fluido y creativo, en el que se reconocen recíprocamente y tienden a la fusión (Alberoni, 2008: 233). ${ }^{6}$ Por su parte, Spivacow ${ }^{7}$ dice que en la pareja, desde la dinámica fusional del enamoramiento, el cuerpo del compañero se vive como una propiedad, una extensión del propio yo.

En esta fase de fusión, se quiere ser uno totalmente, pertenecerse el uno al otro, participar en todo mutuamente y estar de acuerdo en una especie de armonía absoluta, llegando fácilmente a la pérdida de los límites del yo. ${ }^{8}$ Ningún razonamiento, en esta fase, ninguna negación alcanza a anular la esperanza espontánea de un encantamiento. Cada uno siente intuitivamente que se dispone a vivir algo nuevo; que va a posar una mirada nueva sobre el mundo, sobre el compañero y sobre el sí mismo que suprimirá las relaciones anteriores, inaugurando para cada uno una era nueva. En el marco de la relación entre las dos personas de la pareja, cada una se siente fundida con la otra en una fusión que representa algo más que la posesión: representa la desaparición de los límites del yo o, en todo caso, los límites entre una y otra persona. Las dos se funden en una unidad a la que solemos llamar pareja y establecen una frontera común que los separa del mundo exterior. Los amigos, parientes, grupos sociales no parecen soportar esta casi desaparición de uno de los suyos, como si fuera devorado en la relación y quedara perdido para ellos. ${ }^{9}$

Los autores citados coinciden en que en esta fase de elección, de atracción, atrapamiento y establecimiento del vínculo amoroso, existe una fusión entre los miembros de la pareja, una pérdida de los límites yoicos, pero también que es en este momento cuando se sientan las bases de la futura "coalición conyugal", bases sobre las que descansa el vínculo amoroso y sobre las que discurre la estructuración de la pareja, según palabras de Lemaire, en alusión al término utilizado por Linz. En este vínculo queda enmarcado el juego conjunto de los cónyuges a causa de un inconsciente común, al cual Willi (1985) llama colusión, en analogía con los planteamientos que hace Henry V. Dicks. ${ }^{10}$

Según el autor, la colusión indica que la conducta matrimonial de un individuo está determinada por su prehistoria personal, pero determinada también por la actitud vigorizante o amortiguadora del cónyuge, actitud a su vez determinada por el fondo personal suyo. Se puede ver, entonces, que en los miembros de la pareja hay una perturbación fundamental respecto al conflicto conyugal. Aunque actúan en papeles distintos, las perturbaciones en los esposos son análogas e impulsan recíprocamente su comportamiento. Significa que un conflicto conyugal puede basarse en una perturbación fundamental similar, presente en ambos consortes y que esta perturbación es la que está en la base de la atracción que ha sentido el uno por el otro y, en síntesis, del vínculo amoroso que han establecido. La fuerza del vínculo amoroso se encuentra en la conexión que se establece con el conflicto fundamental no superado, sino actuante, en cada uno de los miembros 
de la pareja, poniéndolos en distintos papeles, pero como variantes polarizadas de lo mismo. Es esta una explicación de la fuerza del vínculo amoroso y de la dificultad de romperlo, a pesar de los integrantes de la pareja. Cuando una pareja se divorcia, lo que rompe es el contrato matrimonial, pero no el vínculo amoroso que ha establecido.. Éste existe y existirá, mientras el porqué de la fuerza de su existencia no atraviese la conciencia de cada uno de los miembros de la pareja, lapso durante el cual éstos permanecen atrapados y no podrán ir a establecer otro vínculo con otra persona.

La fuerza del vínculo amoroso está dada por la conexión que se establece con el conflicto fundamental de los miembros de la pareja; más aún, no sólo la fuerza, sino el origen mismo del vínculo está ahí. Por esa razón no atrae nuestra atención cualquier persona, tiene que ser una persona "especial". A modo de ejemplo, podemos observar parte de esta complejidad humana, desde la trinchera de las adicciones, en la película Días de vino y rosas." En ella, Jack Lemmon le da vida a Joe Clay y Lee Remick a Kirsten Arnesen. Se da el encuentro entre estos dos personajes en una lancha, que llevará a Joe y a siete mujeres hasta un yate propiedad de un príncipe árabe que dará una fiesta. Joe se halla frente a siete mujeres hermosas con una de las cuales, Kirsten, tiene puntos de conflicto: la regaña por llegar tarde, le llama la atención por lo mal vestida que va a la fiesta de un príncipe, aunque más tarde se entera que esa mujer no es ninguna de las contratadas para divertir al príncipe, sino que es la secretaría particular del jefe, con quien Joe busca estar siempre en buenas relaciones. Piensa que ha cometido un grave error tratándola de la manera en como lo hizo y quiere componer las cosas. La busca para pedirle una disculpa, le lleva una caja de dulces de cacahuate y todo es conflicto entre ellos: ella rechaza lo que él le dice, también el regalo. En forma sencilla quizá, este primer momento señala tres puntos de conflicto, pero más allá de ellos interesa remarcar que la mirada de Joe queda atrapada en esa mujer y la mirada de ella también en él.
En una primera fase, Joe tiene una relación especial con el alcohol, aunque todavía no se trate de un alcohólico y Kirsten mantiene una relación estrecha con el chocolate, aunque tampoco pueda decirse que se trate de una adicción de ella, en ese momento. Ella no bebe, no prueba ni una sola gota de alcohol a diferencia de Joe. Como sea, se establece el vínculo amoroso entre ellos, se enamoran y en forma apresurada deciden casarse. Tiempo después tienen una hija. Kirsten prueba el alcohol, en una copa de "brandy Alexander", en cuya base está el chocolate y el brandy, que Joe pide le preparen. Gusta mucho del brandy, lo disfruta. Es la forma en que Kirsten se acerca al alcohol y el puente que la lleva de la adicción al chocolate a la adicción al alcohol, quedando en igualdad de circunstancias con Joe.

De esta segunda fase, podemos observar que el alma del vínculo amoroso y el origen del mismo se encuentran en la adicción de ella y la adicción de él. Se funden ambas en el vínculo amoroso que establecen, se pierden los limites yoicos. La adicción está en la parte central de la relación y en la fuerza del vínculo amoroso, que al igual que un tsunami los arrastra a su destrucción y al conocimiento del infierno de ambos.

Al tocar fondo en su miseria humana, Joe toma como tabla de salvación a Alcohólicos Anónimos y le pide a Kirsten haga lo mismo. Ella se niega, no tiene fuerzas, se hunde más en el alcohol. Entre más sobrio permanece Joe, más distante se encuentra de Kirsten. Él acepta que está enfermo e inicia la lucha para permanecer sobrio. Ella no. El hecho marca la distancia entre ellos, la separación, pero no la disolución del vínculo amoroso. Los dos siguen siendo adictos, nada más que Joe tiene conciencia de ello, lo ha aceptado y ha iniciado un camino de lucha para estar sobrio, en tanto que Kirsten no. Más allá de la conciencia que cada uno de estos personajes tenga de su problema y la forma en que lo enfrenta, lo que importa señalar es que el problema como tal sigue existiendo y por lo tanto, el vínculo amoroso entre ambos. Intentamos decir, con esto, que 
tener conciencia del problema no significa eliminarlo, borrarlo o desaparecerlo, significa simplemente ver su existencia y enfrentarlo.

\section{La triangulación amorosa como vía emergente para salvaguardar los límites yoicos y establecer los límites de la pareja}

Una vez establecido el vínculo amoroso, se estructura la pareja y se establecen las bases de su funcionamiento. No analizaremos todos los aspectos que se ocupan o entran en juego para este funcionamiento, simplemente haremos mención de uno de ellos, que entra en acción cuando la pareja, la díada establecida, está en tensión. Se trata de la triangulación.

Se triangula cuando un conflicto intradiádico se desliza a un tercero. Se incluye, pues, a un tercero en la relación, quien permite alcanzar cierto equilibrio durable en la diada, hasta que una de las piezas del triángulo se mueve. Ocurrido tal movimiento, obliga a los miembros del triángulo al restablecimiento de las relaciones anteriormente dadas. La intervención de una tercera persona ocupa la función de fortalecer la posición de uno de sus miembros frente al consorte en conflicto, o a unir más fuertemente a la pareja. Algo se ha escrito sobre esto.

Willi (1985) plantea cuatro formas en que una pareja en conflicto colusivo puede formar un triángulo. Helas brevemente ahí:

a. Aliarse contra un tercero amenazador. Una tensión intradiádica puede neutralizarse dirigiéndola hacia el exterior; es decir, los consortes A y B encuentran una tercera persona, $\mathrm{C}$, a la que consideran como provocación y amenaza común, de modo que deben unirse contra ella, desplazando así las tensiones intradiádicas a un segundo plano. Ejemplos dentro de un matrimonio:

1. Un hijo provoca dificultades deeducación, problema que exige la acción mancomunada de los padres.
2. Uno de los consortes puede sentirse amenazado por sus padres, quienes hacen todo lo posible por destruir su matrimonio.

3. Los vecinos, parientes, dueño de la casa o el patrón molestan a la pareja, la cual tiene que solidarizarse plenamente contra ellos.

b. La tercera persona como amortiguador y vínculo de unión. Para evitar las tensiones matrimoniales o neutralizarlas, es frecuente el ofrecimiento o la aceptación de terceras personas como amortiguadoras o vínculos de unión. Algunas parejas utilizan a los hijos como vínculos de unión. Las parejas, bajo esta fórmula, se protegen de la intimidad excesiva evitando el estar solos. Para conseguirlo procuran tener continuamente cerca de sí a los hijos, los cuales no pueden escaparse de la obligación de servir a los padres como amortiguadores de su unión.

c. La tercera persona como aliado parcial de uno solo de los consortes. Uno de los conyugues, A, hace intervenir a C en el conflicto, como aliado suyo, y así se procura una ayuda protectora contra B. La tensión diádica se hace más fuerte como consecuencia de este tipo de alianzas, pero también es más soportable para uno de los consortes, a costa del otro. La intervención de la tercera persona a favor de un solo consorte es una de las maniobras psicosociales más frecuentes y también de las más peligrosas.

d. Distribución de funciones en la relación matrimonial triangular. En complicidad mutua, consciente o inconscientemente se introduce una tercera persona en la pareja. Esa persona es la que debe asumir aquellos aspectos de la relación que los consortes no pueden hacer efectiva por ellos mismos. Por ejemplo, un marido con tendencias homosexuales puede invitar a su mujer a relaciones extramatrimoniales, o bien, una mujer puede conservar viva, aunque inconsciente, una relación extramatrimonial de su marido, con la que constantemente combate de manera oficial, pero que 
la fuerza a participar de ella, desde una posición de espectadora.

Mario Campuzano Montoya es otro autor que trabaja el triángulo amoroso, en el cual observa una historicidad. Plantea que el triángulo amoroso aparece a partir de la monogamia, como estructura nuclear, y que formas matrimoniales distintas no dan lugar a esta posibilidad. ${ }^{12}$ Hace referencia al trabajo de Henry V. Dicks (1967), quien sostiene que el "acting out sexual" sólo es comprensible a la luz de la dinámica totalizante de la relación diádica y propone una clasificación de la infidelidad, denominándola benigna o maligna, según los efectos de ella en la pareja. Dicks dejaba anotado que, en la "infidelidad benigna", el tercero ocupa el lugar de un objeto transicional que tiene el papel de ser usado por la díada para sus propios propósitos y después desaparecer. La complicidad conciente o inconciente del cónyuge es lo usual en estos casos, así como la función equilibrante o compensatoria del tercero para la díada. Esta necesidad de apoyo mediante un tercero para la díada puede explicar la frecuencia de los amoríos extramaritales. En la "infidelidad maligna", el tercero cumple una función de agresión, devaluación y rechazo encaminado al sometimiento descalificador o separación del cónyuge. Aparece la insensibilidad e indiferencia ante el cónyuge herido. La infidelidad es un arma más para agredir o enloquecer a uno de los cónyuges.

Mario Campuzano Montoya (2002) considera que el proceso emocional en cualquier díada es inestable y frecuentemente busca equilibrarse mediante una relación triangular. Se trata de desplazar el conflicto en los hijos, en diversos miembros de la familia, en personajes extrafamiliares, en el trabajo o en relaciones extramatrimoniales. En todos estos casos, así encubra o intensifique el conflicto marital, el triángulo busca reducir el nivel de angustia e incomodidad, así como estabilizar la pareja temporalmente, hasta que se recupere el equilibrio de la díada. Según este autor, el triángulo amoroso también responde a determinaciones psicológicas menos pragmáticas y psicológicamente más profundas e inconscientes como las que a continuación enumeramos:

a. El triángulo amoroso es la alternativa para evitar o disminuir la relación afectiva o profunda con otro ser humano. Esta relación se desea pero se vive como atrapante. La relación extramatrimonial se vuelve el calmante momentáneo de la ansiedad que provoca ese atrapamiento.

b. El triángulo también es una vía para aquellos individuos que tienen temor a la responsabilidad y el compromiso, al diversificar sus relaciones disminuye ese temor.

c. Eltriánguloseconvierteenla vía de reaseguramiento ante una crisis en la pareja, en lugar de enfrentar el problema adentro, se busca el reaseguramiento afuera.

Lemaire (1990) también se refiere a la forma en que una pareja enfrenta las circunstancias críticas de su vida y utiliza la triangulación. Dice que determinadas situaciones llevan a encarar el problema de la pareja con relación a terceros, terceros que pueden ser miembros de susfamilias, padres, suegros, e, incluso, sus propios hijos u otras personas influyentes con las que están ligados por relaciones de amistad o rivalidad, de colaboración, de trabajo; o también otros compañeros conocidos en experiencias extraconyugales platónicas o sexuales. También considera a otros terceros menos fáciles de definir, porque no son personas concretas, sino objetos poderosamente cargados de sentido por uno u otro de los integrantes de una pareja: la práctica de un deporte, un trabajo particularmente importante, una actividad social, cultural, política o religiosa, etcétera.

Un tercero entre la díada restablece los limites yoicos, pero también protege la relación, según Kernberg, ${ }^{13}$ quien señala que todo hombre y toda mujer teme consciente o inconscientemente la presencia de alguien que sería más satisfactorio para su pareja; este 
tercero es el origen de la inseguridad emocional en la intimidad sexual y de los celos como señal de alarma que protege la integridad de la relación. Esto implica que las relaciones triangulares reflejan colusiones inconscientes en la pareja. En el espacio vincular que se construye en ésta, un concepto que aclara los intercambios que se producen conscientemente y los que conscientemente no tienen lugar, es el de alianzas inconscientes de Rene Kaes. ${ }^{14}$ Existen parejas en las que la relación con terceros ocupa un lugar importante, forma parte de las alianzas inconscientes. Estas alianzas son investiduras entre los sujetos que dan cuenta del nivel de ajuste y estabilización en el intercambio, así como de la relativa homeostasis narcisista de cada polo, elemento fundamental en la pareja. No debe pensárselas como convenios conscientemente estipulados, porque no lo son. Se trata de aquello que configura el mapa de lo permitido y de lo prohibido en la pareja. Alberoni ${ }^{15}$ dice, que entre las muchas formas de construir una pareja se encuentra aquella relacionada con establecer una relación paralela. No algo alternativo, sino algo que se añade a lo existente. El erotismo estimulado por la diversidad, por la novedad. En la mayoría de las parejas, después de un cierto numero de años, el estimulo erótico pierde fuerza, mientras que se despierta en el contacto con personas nuevas y diversas. Es así que se establece una relación que no lleva a la separación o divorcio, sino que sirve para enriquecer la vida cotidiana con un sabor perdido.

La triangulación amorosa, su puesta en escena en algunas cintas del cine mexicano y su presencia en algunas obras de literatura.

Dentro de los dos proyectos de investigación desarrollados en Chiapas - específicamente en medios urbanos- a los que hacemos referencia, uno de los hallazgos más importantes es la presencia de la triangulación como un fenómeno frecuente, tanto en parejas homosexuales como en parejas heterosexuales.

Una particularidad en la relación homosexual, es la de que quien aparece triangulando siempre es una mujer, lo cual quiere decir que uno de los miembros de la pareja homosexual es bisexual. La presencia de la mujer en el triángulo cumple, al menos, tres funciones básicas para el funcionamiento y el equilibrio de la pareja homosexual. ${ }^{16}$

1. La presencia de la mujer como tercero en la relación, proporciona al homosexual una certidumbre sexual sobre la identidad sexual de su pareja (el bisexual). En tanto su pareja también tiene mujer (novia, amante o esposa), corrobora que es hombre de verdad. Hasta puede tener hijos. Si, en cambio, su pareja tuviese otro hombre como tercero (novio o amante) lo pondría en duda.

2. La existencia de la mujer como un tercero en la relación, permite al homosexual entrar en una situación de rivalidad con ella y, de esa manera, saber de su propia identidad sexual.

3. La existencia de la mujer como tercero en la relación, ayuda a guardar las apariencias ante la familia, las amistades y relaciones establecidas en el ambiente laboral y social de quien es componente homosexual en la relación.

Por cuanto se refiere a la pareja heterosexual, quien aparece triangulando frecuentemente es una mujer, aunque no se descarta que quien triangule en estas relaciones sea otro hombre. El fenómeno socio cultural en México en que puede observarse con claridad la triangulación amorosa en la pareja heterosexual, es conocido con el nombre de "casa chica", siempre bajo el esquema de que quien triangula es otra mujer. La fórmula es la de encontrarnos con un hombre, frecuentemente casado con una mujer y en unión libre con la otra, la amante. El primero de los hallazgos en este trabajo específico es el observar que la tensión manifiesta entre los miembros del triángulo, la "casa chica", restablece la estabilidad familiar en la "casa grande", casa oficial. Será esto así, siempre y cuando el triángulo perdure. Esto quiere decir que, más allá de las implicaciones 
culturales, la tensión y la triangulación sólo se instituyen, de manera sostenida, si los tres implicados alcanzan un vínculo amoroso con las características que hemos descrito anteriormente: la fuerza y fortaleza del vínculo, merced a los aspectos inconscientes de cada persona, puestos en juego en la relación y que quedan encapsulados en el vínculo. Se trata de decir, con esto, que si en la pareja se establece un vínculo amoroso entre dos, cuando aparece el tercero se establece un vínculo amoroso entre tres. No existe exclusión de uno. ${ }^{17} \mathrm{El}$ segundo de los hallazgos, relacionado directamente con el primero, es que con la incorporación de un tercero en la relación, la pareja no se disuelve en un porcentaje alto de casos, sino que más bien se fortalece. El tercero de estos hallazgos es aquel que muestra que, en general, las parejas están enteradas de que su compañero tiene una relación amorosa extramatrimonial permanente y no una infidelidad más o menos pasajera; no se considera cuestión de infidelidad. ${ }^{18}$

La triangulación amorosa y, en particular, la figura de la amante, cuando aparece triangulando dentro de la pareja, desempeña algunas de las funciones enlistadas a continuación, según los hallazgos obtenidos en los proyectos que hemos desarrollado en algunas ciudades del estado de Chiapas:

1. La amante aparece como responsable primordial de mantener a la familia unida. ${ }^{19}$ En ese caso, la amante, la "casa chica", figura como apéndice de la familia oficial, como parte de ella, una especie de continuidad que fortalece a la pareja conyugal.

2. La amante que se niega a triangular. Cuando en el matrimonio se llega a la tensión descrita y el triángulo amortiguador no se establece, la relación de pareja pierde toda posibilidad de equilibrio y se rompe.

3. La amante como una persona "muy familiar", cercana de la esposa.

4. La amante como personaje que permite reproducir el ambiente familiar del primer hogar.
5. La amante como prolongación de la esposa, en tanto parecido físico y, que puede poseer el mismo nombre de la esposa.

6. La amante como permanente equilibrio de la monogamia sucesiva.

De todas las variables de triangulación que establece la pareja para disminuir la tensión existente en su interior y restablecer su equilibrio, según describimos en párrafos anteriores, interesa acercarnos a aquella que, llevada a cabo en la relación extraconyugal, incorpora la figura de la amante como un punto de equilibrio, y la vemos ahora ejemplificadas en algunas cintas del cine mexicano y obras de literatura. ${ }^{20}$ Para esta revisión, tomamos como eje los retratos de familia que en éstas se presentan y, sobre todo, el papel o función que juega la figura de la amante en la pareja y familia mexicanas al entrar en este sistema de triangulación amorosa.

Las cintas en cuestión, son las siguientes: La casa chica (1949), La diosa arrodillada (1947), Borrascasen el alma (1954), Tiburoneros (1962), La amante perfecta (1970), y Los hijos de Sánchez (1978). ${ }^{21}$

\section{La amante como responsable primordial de mantener la familia unida}

La amante como responsable de mantener la familia oficial unida (la familia de la casa grande), la encontramos perfectamente descrita en la película La casa chica. ${ }^{22}$ En esta cinta el triángulo amoroso está formado por Fernando (Roberto Cañedo), Lucila (Miroslava, la esposa), Amalia (Dolores del Río, la amante).

La película resulta relevante por varias razones: deviene ejemplar en el desmenuzamiento del fenómeno de triangulación al que alude. En la película La casa chica, se presenta un retrato de familia que aborda una situación frecuente en esas instituciones en México: la presencia de la amante. La familia escogida para presentar el drama, es una de dinero. La esposa, Lucila (personificada por Miroslava), hija de un diplomático, 
tiene el interés de hacer un buen matrimonio y escoge como marido, entre todas sus opciones, a un médico brillante. Roberto Cañedo, Fernando en la película, tras no poder deshacer su promesa de matrimonio con Lucila, le cumple, se casa con ella, aunque sabe que no la ama, pues ha trabajado con Amalia (personificada por Dolores del Río) y está enamorado de ella, una brillante colaboradora en el proyecto para la eliminación de la oncocercosis, en un pueblo de Chiapas. Amalia es estudiante de medicina, pero se vio obligada a suspender sus estudios por cuestiones económicas.

En la película, el papel de la amante es el de ser la responsable primordial de mantener a la familia oficial unida, es ella quien evita la desintegración de la misma. Muchas veces Fernando le dijo a Amalia que se separaría de la esposa, que se divorciaría para irse a vivir con ella definitivamente, y Amalia no lo permitió; más aún, su actitud fue firme cuando llegó el primer hijo al hogar oficial, arguyendo ella que los hijos no pueden quedarse sin padre. Más todavía, en el momento de la muerte de Fernando, la actitud de Amalia en torno a sostener la familia unida se torna inquebrantable: es ella, quien, con la ayuda de uno de sus maestros, hace que Fernando regrese a su casa oficial para morir en ella, cobijado por su familia legal. Es finalmente ella, la amante, quien hace que ese hogar se mantenga unido y no desintegrado, a causa de ella. Como acotación, en la película se muestra que las dos mujeres viven en la ciudad de México, pero en diferentes colonias.

La amante como punto de desequilibrio en la pareja. La imposibilidad de establecer el triángulo y la desaparición de la pareja

La amante como punto de desequilibrio la encontramos caracterizada en la película La diosa arrodillada. ${ }^{23}$ En esta cinta el triángulo amoroso está formado por Antonio Ituarte (Arturo de Córdova), Elena (Rosario Granados, la esposa), y Raquel Serrano (María Félix, la amante).
Antonio es piloto, vuela frecuentemente a la ciudad de Guadalajara, lugar en el que se encuentra establecida la casa de su amante Raquel Serrano, mientras su esposa, Elena, vive en la ciudad de México.

La pareja formada por Antonio y Elena planea celebrar su aniversario de bodas. A propósito de los preparativos para la celebración realizan arreglos a su casa, mandan a construir una fuente. Elena piensa en una Venus de Milo o una estatua linda para esa fuente. Antonio, entonces, le regala a su esposa la estatua de una mujer desnuda (la diosa arrodillada). La modelo para la estatua fue Raquel Serrano, amante de Antonio. Físicamente, las mujeres se encuentran en ciudades diferentes, simbólicamente en la misma casa, una dentro de ella, la esposa, la otra, la amante, en el patio de la casa, en la fuente, como estatua, como diosa arrodillada. Desde el primer momento, Elena siente la proximidad del peligro y advierte a su esposo que nadie podrá separarla de su lado. Mientras Antonio lucha por definir su situación con una sola de las dos mujeres, Raquel le exige que se divorcie de su esposa, es la condición para seguir con él. La esposa muere bajo circunstancias misteriosas el día de la celebración del aniversario de bodas. Antonio debe casarse con Raquel para que no se descubra que su esposa no falleció por causas naturales, aunque, tras la exhumación del cadáver, las autoridades comprueban que no hay asesinato, que Elena murió por causas propias a su enfermedad y dejan libre Antonio, detenido como principal sospechoso. Aunque Raquel se casa con Antonio, siempre está sola, porque la culpa de Antonio en un primer momento no le deja vivir tranquilo; después porque es detenido y, por último, porque se suicida.

Es posible observar en esta cinta que, aunque hay un primer momento de frágil triangulación amorosa, las condiciones de Raquel, las turbulencias de Antonio y, sobre todo, la enfermedad de Elena, no permiten la permanente y duradera relación dentro del triangulo. La primera pieza en moverse es Elena, pues desaparece del escenario con su muerte; la segunda en desaparecer 
es Antonio, quien se suicida. Al final Raquel queda sola. De allí el título de este apartado: la pareja desaparece. En este caso, los miembros de ella mueren; en otros casos, ella solamente se disuelve.

\section{La amante como una persona muy "familiar", cercana de la esposa}

La amante puede ser una persona muy cercana a la esposa: la mejor amiga, la comadre, la sobrina, la tía, la compañera de trabajo, la hermana. Una caracterización de la amante, como personaje familiar cercano a la esposa, se halla muy bien presentada en Borrascas en el alma ${ }^{24}$ cinta en la que la amante es la hermana gemela de la esposa. El filme permite observar una situación frecuente en las parejas que triangulan: el parecido físico de la amante con la esposa. En este caso son iguales físicamente, como dos gotas de agua, son gemelas. En la cinta el triángulo amoroso está formado por Pablo Ibáñez (Roberto Cañedo), Martha (María Elena Márquez, esposa), Alicia (María Elena Márquez, amante y hermana gemela de la esposa).

Pablo Ibáñez es un profesor intratable, enojón. Antes de casarse con Martha fue novio de Alicia, hermana gemela de Martha. Ésta lo traiciona, se va con otro hombre y Pablo, decepcionado y lleno de resentimiento, se casa con Martha, tiene un hijo con ella y vive con ellos, pero parece un hombre amargado que no quiere a su esposa.

Alicia hace su vida por otra parte, pero le va mal, y un día le pide ayuda a su hermana Martha. No tiene adónde ir y le pide que le deje ir a vivir a su casa, con su familia. Martha no puede negarse y, aunque Pablo no está de acuerdo con la decisión de su esposa, ella lo convence. Alicia se incorpora al hogar de Martha, empieza a ganarse al hijo de ésta, juega con él, le ayuda a hacer la tarea, y se propone conquistar nuevamente a Pablo, ahora su cuñado. Al cabo lo consigue, tiene una relación amorosa con él de la que Martha "no sospecha". En este caso las dos mujeres cohabitan la misma casa.
Alicia le propone a Pablo huir juntos con el niño. A Pablo le cuesta tomar la decisión pero al final accede. Cuando esta pareja sale de la casa, Martha le dispara a su hermana Alicia, quien muere al instante. Pablo se suicida y Martha va a la cárcel por el asesinato de su hermana.

En este caso, todo parece indicar que la relación vincular, amorosa, de Pablo, se ha establecido con Alicia, novios antes, amantes después. Aunque Pablo no se casara con ella, permaneció atrapado en ella. Es la pareja que desaparece en este drama. Martha, al parecer, aunque es la esposa, es la que siempre trianguló. Se queda en la cárcel, aunque tras su libertad rehace su vida, también con un amigo de Pablo, su ex esposo. En el drama, el tiempo que vive Pablo con las dos mujeres es relativamente corto, si lo medimos desde que Alicia se incorpora al hogar familiar, pero si tomamos en cuenta que ellos fueron novios, es posible que simbólicamente Alicia haya estado ahí, desde siempre, triangulando. En la película, la historia termina así, trágicamente. La etnografía y el trabajo de campo que realizamos en Tuxtla Gutiérrez y San Cristóbal de Las Casas nos permitió observar este argumento: casos en los que un hombre puede permanecer con dos mujeres hasta el final de sus días y en que ambas mujeres pueden ser hermanas.

\section{La amante como personaje que reproduce el ambiente familiar del primer hogar}

La amante es un personaje que puede proporcionar cariño, cuidados, amor, alegría, un espacio de calidez cuando la esposa y la familia oficial se encuentran lejos del hombre, situación frecuente en una buena cantidad de familias mexicanas. Esta caracterización se ve representada en la película: Tiburoneros. ${ }^{25}$ En la cinta, el hombre de la casa, el jefe de familia, es el único proveedor de recursos económicos, sale de casa casi todo el día por el trabajo y, cuando no lo hay en la ciudad en que vive, lo busca en otros lugares. Por lo general, viaja solo al lugar en donde lo encuentra, no moviliza a su familia. 
Ese hecho establece las bases para que se presenten tres situaciones, igualmente frecuentes dentro de las familias mexicanas; la primera de ellas se refiere a que la esposa se hace cargo del hogar, de la crianza y la educación de los hijos. En la segunda, el hombre se hace cargo económicamente de ese hogar, pero convive poco con su familia; la comunicación se hace vía telefónica, por cartas, fotografías, etcétera. Y la tercera muestra el establecimiento del hombre de un segundo hogar, en el sitio donde se afinca para trabajar.

En esta cinta el triángulo amoroso lo forman Aurelio (Julio Aldama), Adela, la esposa (Amanda del Llano), y Manela, la amante (Dacia González).

Aurelio es un hombre joven que vive en la Ciudad de México con su esposa, cuatro hijos y su madre. Decide ir a trabajar a las costas de Tabasco como pescador de tiburones para mantener a su familia. Se va con las promesas de regresar, de enviar el dinero que gane para que no les falte nada. Y asílo hace: todos los centavos que gana los manda a sus hijos, lo cual es para él una cosa sagrada. A cambio de esto, recibe cartas y fotografías de su familia. Estas últimas las pega en las paredes del barquito, en que pasa la mayor parte del día. Todas las personas que conocen a Aurelio en este lugar, saben que es casado y siempre preocupado por su familia. Allí, en las costas de Tabasco, convive con una familia a la que ayuda económicamente y le proporciona instrumentos para la pesca y mejor calidad de vida a cambio de que la hija joven del señor, Manela, de 18 años, viva con él y lo cuide. La familia de Manela acepta este trato y ella también. Aurelio le promete a Manela cuidarla, hacerle su casita a la orilla del mar y darle lo que necesite. Manela acepta, aun sabiendo que la mayor parte del sueldo de Aurelio se va a la Ciudad de México para su esposa y sus hijos. A Manela le gusta estar con Aurelio, es una muchacha fresca, alegre, que huele a mar. Hace alegre la vida de Aurelio, lo cuida, le da su café caliente, compañía y sobre todo, un hogar para vivir.

Después de tres años de trabajo intenso en ese lugar, su esposa e hijos le piden que regrese, pues lo extrañan. Es difícil para él tomar la decisión, pero finalmente regresa a la Ciudad de México. No obstante, le cuesta adaptarse nuevamente a la vida de ciudad, se siente fuera de lugar en un mundo al que se ha desacostumbrado, triste, pero ve la felicidad que su llegada ha proporcionado a su esposa e hijos. Su esposa se ha encargado del hogar, de la educación de los hijos y él ha convivido poco con ellos, han crecido y siente que los conoce poco. Al no adaptarse de nuevo, y pese a que su madre, quien vive con ellos, le dice: "te debes a tu familia y debes sacrificarte por ella", decide regresar a las costas de Tabasco, pero antes de hacerlo habla con su hijo mayor, a quien le pide que lo comprenda, que cuide a la familia, a su madre, a sus hermanos y que él vendrá más seguido a visitarlos, que ahora está en mejores condiciones económicas para poder hacerlo. Aurelio es un "buen hombre", responsable con los dos hogares que ha establecido. No piensa en disolver ninguno de los dos. Adela, su esposa "no sabe" de la existencia de Manela, pero Manela, sí de la de Adela.

\section{La amante como prolongación de la esposa}

Se ha dicho, en un apartado anterior, que con frecuencia en la figura de la amante se presentan dos características: la primera de ellas muestra la familiaridad o cercanía afectiva que pueda existir entre la amante y la esposa; la segunda, se refiere al parecido físico que en no pocas ocasiones existe entre la amante y la esposa, y que en algunos casos hasta pueden, incluso, llevar el mismo nombre. La película La amante perfecta, ${ }^{26}$ muestra esta segunda característica: la del parecido físico. En ella, el triángulo amoroso está formado por Felipe Arias (Guillermo Murray), Luisa, la esposa (Beatriz Baz) y Mayra, la amante (Fanny Cano).

Un hombre culto, millonario, interesado en el arte, todas las noches, bajo el nombre de Felipe Árias - su verdadero es Miguel Olvera - se apersona en el bar El Limbo. Felipe está casado con Luisa, tiene una hija con ella, pero su matrimonio no es tan estable como parece. 
Su esposa Luisa no deja que se acerque a ella, tiene rencores hacia él, debido a su convicción de que él se casó con ella únicamente por interés, pero tampoco le da el divorcio, porque tiene la conciencia de que debe ser castigado por su engaño. Él trabaja para una firma importante dentro de la empresa de su suegro, el papá de Luisa, y se encarga de su hija. Felipe asiste todas las noches al bar El Limbo para ver el espectáculo de Mayra, la bailarina estelar de ese lugar, hasta que un día contrata sus servicios para que lo acompañe a un lugar que él ya tiene establecido: una cabaña un poco alejada de la ciudad. En ese lugar, Felipe guarda en el closet una colección de vestidos de Luisa. Previamente había mandado a hacer una copia de la ropa de su esposa para tenerla en ese lugar, así como el maquillaje, las pinturas y perfumes que ella usa.

Al llegar esa noche con Mayra a la cabaña, le pide que se cambie de ropa y que se ponga uno de los vestidos del closet. Le da uno muy elegante, le quita la peluca, le pide que se extienda el cabello, se cambie el maquillaje, el labial, etcétera, hasta que la imagen que obtiene es tan parecida a la de su esposa, que incluso cuando la abraza, la llama Luisa. Mucho tiempo actúa así con ella. Mayra lo disfruta como parte de su negocio, hasta se divierte. Pero ambos terminan por involucrarse afectivamente. Felipe le pone un apartamento a Mayra, la saca de trabajar del bar, la transforma en una dama, le enseña a hablar correctamente, le compra ropa, va haciendo que se parezca cada día más a Luisa, su esposa. Incluso le compra un coche con chofer.

Un día Mayra visita a Luisa. Se aterra al saber que todo lo que para ella es una relación hermosa, para Luisa es algo común en su marido, tan común como excéntrico. Le habla de la cabaña, de las amantes en turno, del afán del marido porque todas se parezcan a ella y, sobre todo, de que ella, Luisa, está enterada de la existencia suya, de Mayra y de la relación que tiene con su esposo. Lo que interesa destacar de esta cinta, en primer lugar, es la búsqueda, en Felipe, de una mujer con rasgos físicos parecidos a los de su esposa, pero además, la manera en que induce todo el proceso de transformación, para lograr un parecido aún más cercano.

\section{La amante como equilibrio permanente de la monogamia sucesiva}

La figura de la eterna amante, se halla descrita especialmente en la obra de Oscar Lewis ${ }^{27}$ y, en forma menos exhaustiva, en la película LoshijosdeSánchez. ${ }^{28}$ Jesús Sánchez es un hombre humilde, trabajador, comprador de productos alimenticios para el restaurante La Gloria, en la Ciudad de México. El sueldo que gana lo distribuye en la manutención de tres hogares: el de su esposa, el de su amante y el de una de sus hijas. El triángulo amoroso que Jesús establece permanentemente, queda dibujado de la siguiente forma: Las esposas no cohabitan con élen forma simultánea, sino que las tiene en forma sucesiva. Tras la muerte de una primera esposa, busca otra. A quien sí mantiene en forma simultánea y permanente es a Lupita, su amante, quien está con él desde que Leonor, la primera esposa, vivía, y permanecerá en el mismo rol con Elena, la segunda esposa, y con Dalila, la tercera. ${ }^{29}$

Jesús se casó muy joven con Leonor, a los quince años. Ella era de carácter muy fuerte. Él, buen esposo con ella, nunca la dejó, la sostuvo y vivió con ella hasta el día de su muerte, quedándole cuatro hijos, de quienes Jesús se responsabilizó.

Leonor, Elena y Dalila, son las tres esposas en monogamia sucesiva. Leonor, murió en 1936 dejándole cuatro hijos (Martha, Consuelo, Roberto y Manuel). Seis años después Jesús conoció a Elena, su segunda esposa, quien también falleció. Ella cuidaba a los hijos de él, como si fuera su madre, aunque los dos hombres, Roberto y Manuel, no la quisieron, no la podían ver. Jesús vivió con Elena cinco años, no tuvo hijos con ella, no obstante que se casó con Elena por la Iglesia, porque ella era católica y así se lo pidió. Se casó con ella porque necesitaba que atendiera la ropa, que hiciera las cosas, que le sirviera un café caliente, que cuidara a "los 
chamacos". Necesitaba alguien así en su casa. Aunque tenía a Lupita (su amante), no podía llevarle sus hijos a ella, porque ella a su vez tenía hijos, y los medios hermanos viviendo con padrastros y madrastras no se llevan bien. Elena muere a causa de una enfermedad y Jesús vuelve a quedarse solo con los cuatro hijos, por lo que necesita nuevamente de alguien que le ayude y encuentra a Dalila, quien se comporta como toda una madre para ellos. Cuando Lupita supo de Dalila, se disgustó, pero Jesús habló claro con ella: no tenía por qué enojarse, pues a ella no le faltaba nada. ${ }^{30}$

Lupita y Jesús trabajan en el mismo restaurante. Al entrar en relación con ella, Jesús no pensó en más hijos, pero pronto Lupita quedó embarazada. Lupita tuvo dos hijas pequeñas que reconocían como padre a Jesús, lo respetaban y llamaban "papá". Desde que Jesús comenzó sus relaciones con Lupita, ella sabía que el sueldo de él era muy bajo, que ganaba muy poco, así que sólo pedía que la ayudara con la renta de la habitación en que vivía y con parte de la despensa. Paralelamente, Lupita siguió trabajando siempre en el restaurante.

No deja de llamar la atención, desde la perspectiva de nuestro trabajo, el hecho, aparentemente extraño pero lógico, de que Lupita aparezca en la vida de Jesús desde cuando éste vive con Leonor, su primera esposa, y nunca deja el estatus de "querida", de mujer de la "casa chica", es decir, Jesús busca mujeres para que cuiden a sus hijos, para que vivan en su casa oficial, pero no considera a Lupita para eso. ${ }^{31}$

La triangulación amorosa en tres obras literarias de autores chiapanecos:Florinda, de Flavio Paniagua, Oficio de tinieblas, de Rosario Castellanos y La simiente del corsario, de Cesar Coutiño Bezares.

\section{Florinda ${ }^{32}$}

La novela Florinda (1889) se desenvuelve en el espacio socio-cultural concreto de San Cristóbal de Las Casas. En medio de los acontecimientos sociales de la época, la temática que el autor elije es "la guerra de castas", ocurrida veinte años atrás de la fecha de publicación de la novela. En ese contexto, y con la problemática elegida, construye los personajes que le dan vida y voz. De los acontecimientos que pueden verse en la novela, el que nos importa ponderar es aquel que se refiere a la vida amorosa de tres de los personajes principales, quienes establecen un triángulo amoroso. Se trata de Oppás de Leal, Espartaco y Florinda.

La primera observación que podemos establecer corresponde al hecho de que Florinda es una mujer que aparece con dos amores, relacionada con dos hombres. Vale hacer notar que, dentro de lo que hemos venido revisando, tanto en los trabajos de investigación desarrollados como en las cintas de cine, el "modelo normalizado", el que aparece con más frecuencia, es el de encontrar un hombre relacionado con dos mujeres. Sin embargo, la novela Florinda nos muestra otra posibilidad socialmente menos aceptada en el medio en el que se realiza este trabajo, pero no por ello menos frecuente. ${ }^{33}$

No hemos estudiado este tipo de triangulación, pero derivado de los datos en la novela podemos señalar los siguientes aspectos: La insatisfacción de una mujer por haber establecido un matrimonio por conveniencia, así como la división de sus afectos entre su esposo y su amante. Un esposo poderoso, que conoce de las infidelidades de su esposa, conoce también quién es su rival, pero parece no hacer caso de ello, aunque actúa poniendo obstáculos a los amantes para que estos no logren su felicidad. Espartaco, el amante de Florinda, enamorado de ella, sabe de la infelicidad de su amada, de las locuras de Oppás, su marido, por creerse el Mesías de los indígenas y ante ello, se mantiene cerca de su rival, prudente, para saber qué hacer y cómo actuar para liberar a su amada del cautiverio en que se encuentra. Aquí pueden señalarse tres aspectos:

a. Florinda, la mujer, vive un tormento pasional, se encuentra dividida: ama a Espartaco pero idolatra ideológicamente a su marido. Dice: "yo no puedo vivir engañando a un 
hombre con quien mi familia me casó sólo por conveniencias sociales, porque era ingeniero, ilustrado y descendía de cuna noble". ${ }^{34}$ Florinda no se encontraba contenta ni satisfecha al lado de su esposo; la causa no era conocida, y se murmuraba mucho acerca de las nocturnas reyertas conyugales que paulatinamente fueron haciéndose públicas y ocasionando escándalos, señala el autor (página 51). Señala también la existencia de un matrimonio por conveniencia, la inconformidad de Florinda por ello, y la presencia del amor en la persona del amante.

b. Don Oppás, esposo de Florinda, hombre poderoso, aparentemente carente de vida sexual, vive en el centro de San Cristóbal; conoce de la infidelidad de su esposa, pero sus delirios ideológicos, su ceguedad, le impiden atenderla (página 23). Sabe también con quién lo engaña su mujer y se atreve a decirle a su rival que sólo muerto él podrá ser suya Florinda: "El juramento sacrosanto que demando en nombre de la afección más tierna, más imperecedera, el amor; es un juramento de afecto, es una promesa lisonjera sonriente, dorada, acompañados, si llego a morir en la demanda, vos, Espartaco, seáis el esposo de Florinda" (página 59).

c. Espartaco es Juan Díaz, un indígena de Chamula, quien se distingue por su inteligencia, valor y conducta. Enamorado de Florinda y fiel servidor de Oppás, busca liberar a Florinda del cautiverio en que vive con su esposo y ser feliz con ella. Todos sus movimientos están dirigidos a buscar la liberación de Florinda, siempre cerca de Oppás, para saber qué piensa y qué movimientos realizará. Mientras Oppás se cree el salvador de los indígenas, Espartaco se cree el salvador de Florinda. Al final, el triángulo se resuelve trágicamente, por los acontecimientos políticos antes que por la voluntad de los actores. Los dos varones mueren, y Florinda queda reducida a la soledad. Como si simbólicamente se enunciara la imposible permanencia de esa modalidad de triangulación.

\section{Oficio de tinieblas ${ }^{35}$}

Oficio de tinieblas (1962) es una novela que recrea la atmosfera social mágico-religiosa de Chiapas, en la llamada "guerra de castas". En ese contexto, y desde la recreación que la autora hace, vemos surgir los triángulos amorosos. El primero de ellos es el formado por Leonardo Cifuentes, Isabel Zebadúa (esposa) y Julia Acevedo, La Alazana (amante); el segundo, por Isabel Zebadúa y dos hermanos (aunque no de sangre); el tercero, formado por Julia Acevedo, Fernando Ulloa y Leonardo Cifuentes.

En el primer caso, Leonardo Cifuentes, ayudado por la alcahueta Mercedes Solórzano en sus desmanes con mancebas de la servidumbre e incluso con indígenas, pensaba no tener problemas con su esposa al sostener este tipo de relaciones, por tratarse de mujeres socialmente inferiores a ella; sin embargo, estaba preocupado porque, al relacionarse con La Alazana, los problemas se desatarían, pues socialmente no existían diferencias entre ambas mujeres, además de que la Alazana, en tanto mujer casada, debía cuidar de no despertar los celos del esposo.

Leonardo e Isabel sostienen un matrimonio que ha caído en la rutina, en compañía de una hija enferma (hija de Isabel y su primer esposo), pero interesados en guardar las apariencias. Isabel mantiene silencio ante los deslices de Leonardo, sabe lo que ocurre, aún con La Alazana, por lo que le dice a él: "Yo como patrona no estoy obligada a agasajar a tu querida". ${ }^{36}$ Antes de casarse con Leonardo, Isabel fue esposa de Isidoro Cifuentes. Los padres de Isidoro habían adoptado a Leonardo como hijo, y en vida de Isidoro, Leonardo enamoraba a Isabel y la frecuentaba en el lecho. Cuando 
Isabel enviudó, se casó con ella. De allí que Isabel no le exigiera fidelidad, sino disimulo. ${ }^{37}$

A decir de Isabel, Isidoro era neurasténico, taciturno, atormentado, ansioso, con prolongados e intensos accesos de melancolía que lo torturaban. Era un hombre débil y eso lo explicaba todo: mujeres como Isabel no perdonan la debilidad. Aprecian como signo de hombría el fuete con que el macho doblega a la hembra y guardan el recuerdo de las humillaciones entre las reliquias de amor. Sin embargo, Leonardo, no se tienta el alma para arrastrar por la crin a quien se le resiste, a la que se le muestra indócil, arisca o caprichosa Ahora, Isabel oculta hasta donde le es posible los extravíos de Leonardo, su esposo. La única vez que se arriesgó a quejarse fue en el confesionario y no recibió consuelo, sino la reprimenda de quien harto le había advertido el yerro que iba a cometer al casarse con Leonardo. ${ }^{38}$

En el tercer triangulo, formado por Julia Acevedo, Fernando Ulloa y Leonardo Cifuentes, La Alazana se queja con Mercedes Solórzano de la indiferencia de Fernando, su esposo. Dice: "hemos pasado muchos trabajos juntos, Fernando y yo. No me pesa. Yo estaba conforme porque nos queríamos, pero ahora le han entrado no sé qué ambiciones. Cada día noto más su desapego. Ya no se fija en mi". ${ }^{39}$ En cambio Leonardo Cifuentes estaba, como se dice, "bien picado" por ella. Le mandaba muchos presentes con Mercedes, presentes que ella rechazaba; sin embargo, un día aceptó un perraje de Guatemala, seda bordada, pero no sin advertir a Mercedes: "Dígale usted al señor Cifuentes que no quiero desairarlo, únicamente en consideración de la amistad que le demuestra a mi esposo, estrenaré este chal en el baile de la noche" (página 66).

Fernando Ulloa era un empleado gubernamental. Su misión consistía en levantar los planos de la zona de Chamula para adjudicar los ejidos a las comunidades indígenas y establecer en los latifundios el régimen de pequeña propiedad exigido por la ley (página 125). Casado con Julia, no tenía hijos. Su mujer no parecía ser abnegada. Tampoco se preocupaba de la infidelidad.
De los tres triángulos amorosos que en este apartado mostramos, importa destacar los siguientes aspectos:

a. En dos de ellos, se muestra a la mujer en dos roles, como esposa y amante. Son Julia Acevedo, la Alazana e Isabel Zebadúa, quienes aparecen relacionadas con dos hombres al mismo tiempo. Casos parecidos al de Florinda, la novela que vimos con anterioridad. Los tres ubicados en San Cristóbal de Las Casas. En los tres casos, los hombres se conocen, tienen relaciones de amistad, cercanía afectiva e intuyen lo que ocurre con sus esposas, sin embargo guardan silencio.

b. Sorprende quizás aún más el que Isabel se relacione con dos hermanos, es claro que no de sangre, pero en tanto que Leonardo Cifuentes fue adoptado por los padres de Isidoro. En el modelo convencional, derivado del trabajo de campo, es frecuente encontrar un hombre relacionado afectivamente con dos hermanas, una como esposa y la otra como amante.

c. Tanto Leonardo Cifuentes como Julia Acevedo están casados. Con el hecho de su relación amorosa, establecen dos triángulos simultáneos. Parece que no hay engaños entre cuantos forman los triángulos amorosos.

La simiente del corsario:

En la novela La simiente del corsario, ${ }^{40}$ situada en los valles centrales de la Frailesca en Chiapas, vemos también aparecer los triángulos amorosos. En este caso, formados por Alberto Corzo, Josefina Rodríguez (esposa) y Juventina Fernández (amante).

Alberto se hallaba entre dos amores, En Villa Flores, su compromiso de casamiento con Josefina Rodríguez no se podía alargar presentando las mismas excusas de otros años. ${ }^{41}$ Sin embargo, en una visita a Ocozocoautla, conoce a Juventina Fernández, de quien se enamora perdidamente y con quien vive los episodios más 
importantes de su vida revolucionaria. En su caso, ama a las dos mujeres con la misma intensidad. Pensaba, por momentos, que lo lógico sería tener casa chica y casa grande, planteándoselo con esa claridad; es decir, tener como esposa a una y como amante a la otra. Las dos mujeres lo amaron desde el momento de conocerlo: Josefina desde niña. Juventina desde que lo conoció. Alberto pensaba que Juventina, nacida en otro pueblo distinto del suyo, también merecía el calificativo de novia de toda la vida y, en su momento, de esposa. ${ }^{42}$ Finalmente, se casa con Josefina Rodríguez, con quien tiene un hijo y en cuya casa muere, a solicitud expresa de Juventina, pero mantiene su casa chica con esta Juventina Fernández, hasta el día de su muerte.

De esta novela podemos señalar dos puntos importantes:

a. La triangulación amorosa se construye como tal desde el tiempo del noviazgo de Alberto con Josefina.

b. Cuando se casa Alberto, la amante ya existe y conoce la situación en la que se encuentra.

\section{Una reflexión conclusiva}

Hemos intentado un recorrido breve en torno al fenómeno de la triangulación amorosa; según señalamos, no como un fenómeno excepcional o aislado en la sociedad mexicana, sino como un hecho dado, culturalmente aceptado y, en tanto eso, normalizado, según se corrobora en los datos de campo y en el trabajo de tesis "La casa chica" en Chiapas. Un acercamiento antropológico», que se desprende de ellos. Nuestro intento ha sido el de reconocer sus formas de expresión en algunas cintas del cine mexicano, sabiendo quelas hay muchas más, así como en algunas novelas chiapanecas. Quedan de lado un buen número de novelas mexicanas, obras de teatro y la inmersión en las telenovelas, sin duda inductoras magistrales de la reproducción cultural de aquello que sea y deba ser la familia mexicana, con todo y su apéndice triangular, "la casa chica" o alguna expresión alternativa. Un tanto como decir, "la familia nuclear, célula formativa de la sociedad mexicana, su piedra angular, es necesaria para cumplir esa función social"; no es cuestionable; no puede ponerse en tela de juicio esa extensión: "la gran familia mexicana". Ha vivido, vive y vivirá, unida, sólida, ejemplar, así requiera de su apoyo o extensión en la figura normativa de la triangulación, pero un triangulación que no trata de una "cana al aire", como se dice, de una infidelidad pasajera, sino de una permanencia estructural, legitimada por el reconocimiento social y su reproducción en todos los sectores y ámbitos de la sociedad.

\section{Notas}

${ }^{1}$ El trabajo tiene como base los resultados empíricos obtenidos en dos proyectos de investigación en el estado de Chiapas. El primero de ellos, enfocado en parejas homosexuales hombres, realizado entre 1996-2000; elsegundo, con parejas heterosexuales, entre 20042009. El punto de convergencia entre ambos proyectos se sitúa en el interés de saber qué ocurre cuando un hombre y una mujer deciden formar pareja, más allá de institucionalizarla o no vía matrimonio civil o religioso, qué tipo de relación afectiva establecen, y la influencia en ellas del marco sociocultural en el que se instauran. Uno de los hallazgos más importantes en estos trabajos fue encontrar en forma frecuente la triangulación. Es decir, un tercero afectando la relación de pareja.

2 Vid. "La casa chica en Chiapas. Una aproximación antropológica", nota núm. 17 (defendida para obtener el grado de Doctor ante la Facultad de Psicología, Programa de Psicología Social y Antropología de las Organizaciones, de la Universidad de Salamanca, España).

3 Alejo Spivacow, Miguel: La pareja en conflicto. Aportes psicoanalíticos, Paidós, Argentina, 2011.

${ }^{4}$ Encontramos trabajos que dan cuenta de este aspecto desde 1905 a la fecha. Véase, por ejemplo, Sigmund 
Freud, "Tres ensayos de teoría sexual", en Fragmento de un caso de histeria (Dora), Tres ensayos de teoría sexual y otras obras, 1901-1905 [1996]. Tomo VII, Amorrotu Editores; "Sobre un tipo particular de elección de objeto en el hombre (contribuciones a la psicología del amor, II. 1912)"; "Sobre la más generalizada degradación de la vida amorosa (contribuciones a la psicología del amor, II. 1912)", en Cinco conferencias sobre psicoanálisis, un recuerdo infantil de Leonardo Da Vinci y otras obras. Tomo XI. 1910 [1996]. Amorrortu Editores; "Recordar, repetir, reelaborar (nuevos consejos sobre la técnica del psicoanálisis II. 1914)", en Sobre un caso de paranoia descrito autobiográficamente (Schreber), Trabajos sobre técnicas psicoanalíticas y otras obras. Tomo XII. 1911-1913 [1996]. Amorrortu Editores. Henry V Dicks: Tensiones matrimoniales. Buenos Aires Argentina: Hormé, 1970. Jean G. Lemaire: La pareja humana: su vida, su muerte, su estructura, México: Fondo de Cultura Económica, 1986 [1979]. Jurg Willi: La pareja humana: relación y conflicto. Madrid, España: Ediciones Morata, 1985[1978]. Jacques Alain Miller et al. La pareja y el amor, Buenos Aires Argentina: Paidós, 2003. Mario Campuzano Montoya. La pareja humana: Su psicología, sus conflictos, su tratamiento, Plaza y Valdez. México, 2002. Carles Pérez Testor, Parejas en conflicto, España: Ediciones Paidós, 2006. José Navarro Góngora et al. Parejas en situaciones especiales. España: Paidós, 2000. Estos son algunos de los trabajos que sostienen que en la elección y formación de la pareja están presentes aspectos inconscientes.

5 Vid. "La elección de la pareja", en Parejas en conflicto, (2006: 65).

${ }^{6}$ Alberoni Francesco, Te amo, España: Gedisa, 2008.

${ }^{7}$ Vid, Alejo Spivacow, Miguel, La pareja en conflicto. Aportes psicoanalíticos, $(2011,163)$.

${ }^{8}$ Vid. Jurg Wiili, La pareja humana: relación y conflicto, (1985: 25).

9 Vid. Lemaire, La pareja humana, su muerte, su estructura, (1990).

${ }^{10}$ Willi, La pareja humana: relación y conflicto (1985); Henry V. Dicks, Tensiones matrimoniales, La aserción de Willi, en torno a la colusión en la pareja, se ve ejemplificada en la película Secretos de un matrimonio ("Scenes from a marriage"), de Ingmar Berman, en que el cineasta escenifica puntualmente algunas de las conductas frecuentes en la pareja.

"Días de vino y rosas es una película estadounidense de 1962, dirigida por Blake Edwards. Protagonizada por Jack Lemmon, Lee Remick, Charles Bickford, Jack Klugman, ganadora del Óscar a la mejor canción, es un estudio de lo destructivo que pueden ser las adicciones en la vida moderna. Este film muestra una particularidad con respecto al alcoholismo; la tendencia latente a adquirirlo.

${ }^{12}$ Campuzano Montoya, Mario. Laparejahumana:supsicología, sus conflictos, su tratamiento. Plaza y Valdez, México, 2002.

${ }^{13}$ Kernberg Otto. Relaciones amorosas. Normalidad y patología, Argentina: Paidós, 2009.

${ }^{14}$ Vid. ibídem: 47.

${ }^{15}$ Vid Alberoni Francesco, Te amo, España: Gedisa, 2008, pp. 177.

${ }^{16}$ Ver estos resultados publicados en, Magda Estrella Zúñiga Zenteno, Entre los laberintos de la vida amorosa, Universidad de Ciencias y Artes de Chiapas, Tuxtla Gutiérrez, Chiapas, 2002.

${ }^{17}$ Esta investigación fue desarrollada en dos ciudades del estado de Chiapas: Tuxtla Gutiérrez y San Cristóbal de Las Casas y constituye la tesis doctoral titulada "La casa chica en Chiapas. Una aproximación antropológica", defendida para obtener el grado de Doctor ante la Facultad de Psicología, Programa de Psicología Social y Antropología de las Organizaciones, de la Universidad de Salamanca, España.

${ }^{18}$ La investigación llevada a cabo por el Kinsey Institute, considerada por los expertos como la fuente de investigación más fiable disponible sobre el sexo, muestra que el $90 \%$ de las personas con pareja infiel saben que sus parejas les han traicionado. Además, casi $80 \%$ de las parejas en las que uno de sus miembros ha sido infiel siguen juntos y tratan de solucionar sus problemas. Raymond B. Green. Infieles. 180 signos 
reveladores de la infidelidad en la pareja. Amat editorial. España, 2004.

19 En terapia, una mujer le dice a Hellinger, su terapeuta: "Cuando me enteré la pase muy mal (se refiere a que su marido tiene otra mujer). Durante el tiempo siguiente se mostró que entre nosotros cambió y se disolvió mucho, y que ahora, aquello que hay entre nosotros dos, ha aumentado". Responde el terapeuta: "Exacto. Quizá fuera necesario para fomentar la relación. Si se mira sin juicios morales, simplemente fijándose en los efectos, muchas veces el significado es otro. En lograr el amor en la pareja. El trabajo terapéutico de Bert Hellinger con parejas. Johannes Neuhauser editor, Herder, España, 2008, pág. 200.

${ }^{20}$ Para su estudio en detalle, ver: "La casa chica en Chiapas. Una aproximación antropológica”, nota 17.

${ }^{21}$ Esta última película, producida en Estados Unidos, pero basada en el trabajo antropológico de Oscar Lewis realizado en la Ciudad de México titulado: Los hijos de Sánchez, y publicado en su primera versión en español por el Fondo de Cultura Económica en 1964.

${ }^{22}$ La casa chica Película mexicana, (1949). Protagonizada por Dolores del Río, Roberto Cañedo y Miroslava, con Argumento de José Revueltas, adaptada por Roberto Gavaldón y José Revueltas. Dirigida por Roberto Gavaldón.

23 La diosa arrodillada (1947), Película mexicana. Protagonizada por Arturo de Córdova, Rosario Granados y María Félix. Argumento de José Revueltas y Roberto Gavaldón, basado en un cuento de Ladislao Fodor.

24 Borrascas en el alma (1954). Película mexicana. Protagonizada por Roberto Cañedo y María Elena Márquez. Guión de Ismael Rodríguez y Carlos Orellana. Melodrama basado en la obra de Luis G. Basurto: Frente a la muerte.

${ }^{25}$ Tiburoneros (1962). Película mexicana. Guión y dirección de Luis Alcoriza. Protagonizada por Julio Aldama, Amanda del Llano y Dacia González.
${ }^{26}$ La amanteperfecta (1970). Película mexicana. Protagonizada por Fanny Cano, Guillermo Murray y Beatriz Baz. Dirigida por José Díaz Morales. Guión escrito por Hugo Arguelles.

${ }^{27}$ Óscar Lewis. Los hijos de Sánchez. Editorial Grijalbo. México. 2003 [1961].

${ }^{28}$ Los hijos de Sánchez, (1978). Película estadounidense. Protagonizada por Anthony Quinn, Dolores del Río, Katy Jurado, Helena Rojo, Lupita Ferrer, Lucia Méndez, Carmen Montejo, Ignacio López Tarso, Héctor Bonilla, Patricia Reyes Espíndola, Patricia Aspillaga, José C. Ruiz, Enrique Lucero, Rebeca Silva, José Chávez, Josefina Echanove, Rene Cardona Sr. Elsa Benn, Armando Silvestre. Dirigida por Hall Bartlett. Basada en el trabajo antropológico de Oscar Lewis, publicado en su primera edición en español en 1964. En ese trabajo, el autor ofrece la biografía de una familia mexicana humilde de finales de los años 50.

${ }^{29}$ Elena, es la segunda esposa de Jesús Sánchez, la conoció seis años después de la muerte de Leonor. Esto, según el texto de Oscar Lewis, Los hijos de Sánchez. Editorial Grijalbo. México. 2003 [1961: 16]. Elena no aparece en la película Los hijos de Sánchez que revisamos ahora, en la cual sólo aparecen Leonor y Dalila como esposas, y Lupita como amante, pero nos parece importante mencionarla.

${ }^{30}$ Lewis, op. cit., 2003).

${ }^{31}$ Lewis, 2003: 505.

32 Flavio Antonio Paniagua Ruiz (1843-1911). Nació en San Cristóbal de las Casas. En Florinda, aparece el autor de esta obra "como un testigo ocular de los hechos, como un escritor que da cuenta de una realidad vivida y sufrida en carne propia, como un autor que narra hechos vividos; pero, habría que agregar, hechos recordados, recordados-imaginados, reconstituidos en su imaginería": Amando M. Colunga. Prologo de Florinda en su segunda edición. Serie Literatura. Universidad de Ciencias y Artes de Chiapas. Tuxtla Gutiérrez Chiapas. 2003 [1889].

60

Revista LiminaR. Estudios socialesy humanísticos, año 9, vol. IX, núm. 2, diciembre de 2011, San Cristóbal de Las Casas, Chiapas, México. ISSN: 1665-8027 
${ }^{33}$ Como dato adicional es de señalar que dentro del trabajo de investigación desarrollado para la Tesis Doctoral "La casa chica en Chiapas. Una aproximación Antropológica" y presentado para su defensa en septiembre del 2009, queda registrado este modelo alternativo y la frecuencia con que ocurre de encontrar a una mujer relacionada con dos hombres; esposo y amante en San Cristóbal de las Casas.

${ }^{34}$ Flavio Paniagua, Florinda, Universidad de Ciencias y Artes de Chiapas, Tuxtla Gutiérrez; Chiapas, 2003, página 56.

${ }^{35}$ Rosario Castellanos (1925-1974), nació en la Ciudad de México. Después de su nacimiento la trajeron a vivir a Comitán de Domínguez, Chiapas. Después volvió a la Ciudad de México.

${ }^{36}$ Castellanos, 1988, p. 68.

${ }^{37}$ Castellanos, 1988, p. 72.

${ }^{38}$ Castellanos, 1988, pp. 74-77.

${ }^{39}$ Idem, p. 65.

${ }^{40}$ CesarCoutiño Bezarez(1917-1990). Nacióen Ocozocoautla de Espinoza. Publicó su novela La simiente del corsario en 1953. Aunque el autor no lo dice, La simiente del corsario trata de novelar la gesta mapachista y, en particular las hazañas de un personaje controvertido, el mapachista Sinar Corzo, que tiene vida en la novela, con el nombre de Alberto. Jesús Morales Bermúdez. "De mapaches y carracas. Una novela de la revolución", en Independencias, revoluciones y revelaciones: doscientos años de literatura mexicana. Universidad Veracruzana/University of Texas/ UC mexicanistas, México, 2010.

${ }^{41}$ Cesar Coutiño Bezarez. La simiente del corsario. Comercializadora de impresos. Tuxtla Gutiérrez, Chiapas, 2001.

${ }^{42}$ Coutiño Bezárez, 2001, p. 438.

\section{Bibliografía}

Alberoni, Francesco (2008), Te amo, España: Gedisa.

Alejo Spivacow, Miguel (2011), Lapareja en conflicto. Aportes psicoanalíticos, Argentina: Paidós.
Campuzano Montoya, Mario (2002), La pareja humana: Su psicología, sus conflictos, su tratamiento, México: Plaza y Valdez.

Castellanos, Rosario (1988 [1962]), Oficio de Tinieblas, México: Joaquín Mortiz.

Coutiño Bezárez, César (2001 [1953]), La Simiente del Corsario, Tuxtla Gutiérrez, Chiapas:Comercializadora de impresos.

Dicks, Henry V. (1970), Tensiones matrimoniales, Buenos Aires Argentina: Hormé.

Freud, Sigmund, "Tres ensayos de teoría sexual", en Fragmento de un caso de histeria (Dora), Tres ensayos de teoría sexual y otras obras. 1901-1905 [1997], Tomo VII. Amorrotu Editores. Buenos Aires, Argentina. 1996.

Freud, Sigmund (1996), "Sobre un tipo particular de elección de objeto en el hombre (contribuciones a la psicología del amor, II. 1912)" y "Sobre la más generalizada degradación de la vida amorosa (contribuciones a la psicología del amor, II. 1912)", en Cinco conferencias sobre psicoanálisis, Un recuerdo infantil de Leonardo Da Vinci y otras obras, Tomo XI. 1910 [1996], Buenos Aires, Argentina: Amorrortu Editores.

Freud, Sigmund (1996), "Recordar, repetir, reelaborar (nuevos consejos sobre la técnica del psicoanálisis II. 1914)", enSobreuncasodeparanoiadescritoautobiográficamente (Schreber), Trabajos sobre técnicas psicoanalíticas y otras obras, Tomo XII. 1911-1913 [1997], Buenos Aires, Argentina: Amorrortu Editores.

Green Raymond B. (2004 [2000]), Infieles. 180 signos reveladores de la infidelidad de la pareja, España: Amat Editorial.

Kernberg, Otto (2009), Relaciones amorosas. Normalidad y patología, Argentina: Paidós.

Lemaire, Jean G. (1986 [1979]), La pareja humana: su vida, su muerte, su estructura, México: Fondo de Cultura Económica.

Lewis, Oscar (2003 [1961]), Los hijos de Sánchez México: Editorial Grijalbo.

Miller, Jacques Alain et.al (2003), La pareja y el amor, Buenos Aires, Argentina: Paidós. 
Morales Bermúdez, Jesús (2010) "De mapaches y carracas. Una novela de la revolución”, en Independencias, revoluciones y revelaciones: doscientos años de literatura mexicana, México: Universidad Veracruzana/ University of Texas/UC mexicanistas.

Navarro Góngora, José et al. (2006), Parejas en situaciones especiales, España: Paidós.

Neuhauser, Johannes (editor) (2008 [1999]), Lograr el amor en la pareja. El trabajo terapéutico Bert Hellinger con parejas, España: Herder.

Paniagua, Flavio A. (2003 [1889]) Florinda, Tuxtla Gutiérrez, Chiapas: Universidad de Ciencias y Artes de Chiapas.

Pérez Testor, Carles (2006), Parejas en conflicto, España: Paidós.

Willi, Jurg (1985[1978]), La pareja humana: relación y conflicto, Madrid: Ediciones Morata.

Willi, Jurg (2004), Psicología del amor, España: Herder.

\section{Cintas de cine, revisadas}

1. La casa Chica (1949), Protagonizada por Dolores del Río, Roberto Cañedo y Miroslava, Argumento de José Revueltas, adaptada por Roberto Gavaldón y José Revueltas, Dirigida por Roberto Gavaldón, Colección, grandes de nuestro cine, México.

2. La diosa arrodillada (1947), Protagonizada por Arturo de Córdova, Rosario Granados y María Félix, Argumento de José Revueltas y Roberto Gavaldón, basado en un cuento de Ladislao Fodor, Colección, México en pantalla, México.

3. Borrascas en el alma (1954), Protagonizada por Roberto Cañedo Y María Elena Márquez, Guión de Ismael Rodríguez y Carlos Orellana, Melodrama basado en la obra de Luis G. Basurto:
Frente a la muerte. Colección, el cine de oro mexicano, México.

4. Tiburoneros (1962), Protagonizada por Julio Aldama, Amanda del Llano y Dacia González. Guión y dirección de Luis Alcoriza, Colección, las grandes del cine mexicano: 50s y 60s, México.

5. La amante perfecta (1970), Protagonizada por Fanny Cano, Guillermo Murray y Beatriz Baz, Es una cinta, dirigida por José Díaz Morales, Guión escrito por Hugo Argüelles, Colección Vive México, México.

6. Los hijos de Sanchez (1978), protagonizada por Anthony Quinn, Dolores del Río, Katy Jurado, Helena Rojo, Lupita Ferrer, Lucia Méndez, Carmen Montejo, Ignacio López Tarso, Héctor Bonilla, Patricia Reyes Espíndola, Patricia Aspillaga, José C. Ruiz, Enrique Lucero, Rebeca Silva, José Chávez, Josefina Echanove, Rene Cardona Sr. Elsa Benn, Armando Silvestre. Es una cinta dirigida por Hall Bartlett, basada en el trabajo antropológico de Oscar Lewis: Los hijos de Sanchez, publicado en su primera edición en español en 1964, Colección, Cine clásico, México.

7. Días de vino y Rosas (1962), Protagonizada por Jack Lemmon, Lee Remick, Director: Blake Edwards. Colección, cine de oro, Estados Unidos

8. Secretos de un matrimonio (1973), Protagonizada por Liv Ullman, Erland Josephson. Dirigida por Ingmar Bergman, Suecia.

9. Infiel (2000), Protagonizada por: Lena Endre, Krister Henriksson, Erland Josephson, Thomas Hanzon, Michelle Gylemo. Directora: Liv Ullmann. Guión: Ingmar Bergman. Intérpretes: Lena Endre, Krister Henriksson, Erland Josephson, Thomas Hanzon, Michelle Gylemo, Suecia. 